\title{
Hydrogen: State of the art and directions of future
}

\section{use}

\begin{abstract}
The use of hydrogen as one of the most promising areas of European Green Deal, i.e. the transition to a carbon-free economy (decarbonization) is considered. In the world energy sector, the problem of production and use of "green" hydrogen produced by electrolysis attracts considerable attention. Per $1 \mathrm{~m}^{3}$ of electrolytic hydrogen consumes from 4 to $5 \mathrm{kWh}$ of electricity, despite the fact that it contains chemical energy of $3.0 \mathrm{kWh}$. The calorific value of hydrogen is 3.3 times less than that of methane. Hydrogen properties such as wide explosive limits, high torch propagation speed, and corrosion activity against many metals require special measures during transportation, storage, and use. Economically justified technologies for the use of hydrogen do not yet exist. As one of the effective options are considered the prospects of transporting a mixture of hydrogen and natural gas by main and distribution pipelines. Most hydrogen projects are funded by a grant. The driver of hydrogen energy is the prevention of anthropogenic impact on climate change, which in itself is problematic. Bibl.9, Table 1.
\end{abstract}

Volume 7 Issue I - 202 I

\section{Karp IM}

Academician of the Nat. Ac. Sc. of Ukraine, The Gas Institute of the Nat. Ac. Sc. of Ukraine, Ukraine

Correspondence: Karp IM,Academician of the Nat. Ac. Sc. of Ukraine, The Gas Institute of the Nat. Ac. Sc. of Ukraine, 031 I 3 Kyiv, 39 Degtyarivska St., Ukraine, Tel +380 6746630 74, Emailkarpkiev@gmail.com

Received: February 19, 2021 | Published: February 26, 2021

Keywords: hydrogen, properties, transportation, storage, economy, problems

\section{Hydrogen as a trend in modern energy}

At present, the problem of production, transportation and use of hydrogen is almost the main trend in world energy. There are many projects of various technologies of its production, replacement of traditional energy sources, prospects of use as transport fuel, as energy accumulator, renewable and fuel gas in metallurgy, use in mixtures with natural gas in household heaters as an environment for energy transportation. Almost all projects were implemented with government grants. Hydrogen issues are given a lot of attention in the media and speeches of major politicians. Hydrogen energy programs are being adopted at the state level. Some countries (Japan, Austria) have even announced a complete transition to this energy source and have identified themselves as "hydrogen" countries. The number of publications on hydrogen is so vast that it is not possible to make a general overview of them.

\section{Properties}

Hydrogen has been known to mankind for more than 250years. Hydrogen is a chemical element with atomic number 1, "the simplest representative of all chemical elements in general" (Wikipedia). Two atoms of the chemical element hydrogen form the substance "hydrogen", the lightest gas without smell, color and taste. Poorly soluble in water and other solvents, well - in many metals - iron, nickel, platinum, palladium. Due to its extremely small size, the hydrogen molecule diffuses into the crystal lattice of the metal. Diffusion of hydrogen into the metal leads to the phenomenon of so-called hydrogen corrosion. The mechanism of corrosion is not definitively defined. It has been hypothesized that hydrogen interacts with carbon dissolved in the metal to form methane, which as the process progresses and the pressure increases, breaks the intergranular bonds, leading to the destruction of the metal. With increasing temperature to $200^{\circ} \mathrm{C}$ and above, the corrosion process is significantly accelerated. There are other hypotheses to explain the mechanism of hydrogen corrosion. Thermophysical characteristics of hydrogen in comparison with the properties of natural gas are given in Table 1. The lower calorific value of hydrogen is $3.0 \mathrm{kWh}$, higher $-3.55 \mathrm{kWh}$. Table 1 show that the energy value of hydrogen at the lower heat of combustion is 3.3 times less than methane. This should be taken into account in the calculations of pipelines and burners choice in the case of replacement of natural gas with hydrogen. In the process of using hydrogen in boilers and in transport, special safety requirements must be observed because to its high flammability and high speed of flame propagation. Due to the high permeability of hydrogen conventional materials are unsuitable for its transportation and storage because to hydrogen corrosion. Existing gas networks are not suitable for transporting pure hydrogen. Hydrogen pipelines require other materials, different welding technology, compressors, sensors, safety equipment. The possibility of leakage in the joints and fittings due to high pressure increases.

\section{Production}

Currently, it is produced in the world about of 70 million tons, two thirds of which are used in the production of mineral fertilizers, and about one third in the oil refining industry in the processes of hydrogenation and desulfurization. Around $95 \%$ of this hydrogen is produced by the reforming (conversion) of hydrocarbons or coal. It is called "gray" because its production is accompanied by emissions of carbon dioxide $-10 \mathrm{~kg} \mathrm{CO}_{2} / \mathrm{kg} \mathrm{H}_{2}$. "Blue" refers to the hydrogen obtained by the conversion, with carbon dioxide being removed from the converted gas mixture and stored (CCS process - Carbon Capture and Storage). The cost of $\mathrm{CO}_{2}$ utilization is 70euros/t. A small amount of hydrogen $(1-5 \%)$ is produced by electrolysis, it is called "green". It is used for machinery and food industry. Such hydrogen is considered for possible widespread use. At this time, there is no economically viable technology to use "green" hydrogen. This is due to the high cost of its production, its thermophysical properties and features of transportation and storage. ${ }^{1}$ The process of electrolysis is an endothermic process of decomposition of water by electric current:

$$
\mathrm{H}_{2} \mathrm{O}(\mathrm{w})+286 \mathrm{~kJ}=\mathrm{H}_{2}(\mathrm{~g})+1 / 2 \mathrm{O}_{2}(\mathrm{~g})
$$


Table I Thermophysical characteristics of hydrogen

\begin{tabular}{|c|c|c|c|c|c|c|c|}
\hline \multirow[b]{2}{*}{$\begin{array}{l}\text { Flammable } \\
\text { gas }\end{array}$} & \multicolumn{7}{|l|}{ Parameters } \\
\hline & $\begin{array}{l}\text { Lower heat of } \\
\text { combustion Q। } \\
\mathbf{k J} / \mathbf{m}^{3} \\
\left(\mathbf{k c a l} / \mathbf{m}^{3}\right)\end{array}$ & 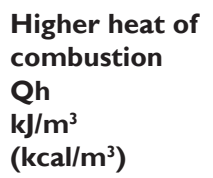 & $\begin{array}{l}\text { Qh/QI } \\
\%\end{array}$ & $\begin{array}{l}\text { Ignition } \\
\text { temperature } \\
{ }^{\circ} \mathrm{C}\end{array}$ & $\begin{array}{l}\text { Ignition limits in } \\
\text { mixture with air } \\
\%\end{array}$ & $\begin{array}{l}\text { Calorimeter. } \\
\text { combustion } \\
\text { temperature, } \\
{ }^{\circ} \mathrm{C}\end{array}$ & $\begin{array}{l}\text { Norm. flame } \\
\text { propagation } \\
\text { speed,* } \\
\mathrm{m} / \mathrm{sec}\end{array}$ \\
\hline $\mathrm{CH}_{4}$ & $\begin{array}{l}35739 \\
(8550)\end{array}$ & $\begin{array}{l}39500 \\
(9450)\end{array}$ & 111 & 645 & $5-15$ & 2211 & 0,28 \\
\hline $\mathrm{H}_{2}$ & $\begin{array}{l}10800 \\
(2580)\end{array}$ & $\begin{array}{l}12767 \\
(3054)\end{array}$ & 118 & 510 & $3,3-81,5$ & 2380 & 1,6 \\
\hline
\end{tabular}

*other sources give values for $\mathrm{CH}^{4},-0.37$; for $\mathrm{H}^{2}-2.7-4.8 \mathrm{~m} / \mathrm{sec}$

The value of $286 \mathrm{~kJ} / \mathrm{kmol}$ corresponds to an electric energy consumption of $3.55 \mathrm{kWh} / \mathrm{m}^{3}$. According to the first law of thermodynamics - the law of conservation of energy - it is impossible to "bypass" this value. The cost of production by conversion is $2-5$ times less than by electrolysis. The consumption of electricity for the production of $1 \mathrm{~m}^{3}$ of hydrogen by electrolysis is on average $5 \mathrm{kWh}$, and in the best modern electrolyzers - $4 \mathrm{kWh}$, i.e. the energy component in the cost of electrolytic hydrogen will be \$ 0.9-2.25/ $\mathrm{m}^{3}$. It should be noted that the cost comparison of the efficiency of hydrogen production with other energy sources is conditional, i.e. price conditions vary in different regions of the world and countries. In, ${ }^{2}$ the efficiency of hydrogen production by electrolysis in relation to the primary fuel is estimated at $23 \%$. Power Engineering International Journal notes 5 global hydrogen projects that, according to the authors of the review, can change the overall picture of hydrogen energy. ${ }^{3}$ These include: 1) HyDeploy green energy trial UK. The project demonstrates an injection of $20 \%$ vol. hydrogen to the existing Keele University gas distribution network, which supplies gas to up to 30 university and 100 residential buildings. The safety of using such a mixture in the network has been proven. Details of the project can be found in. ${ }^{4}$ A similar project was also carried out by Engie in northern France. 2) Electrolysis facility in the Greater Copenhagen area - Denmark. The project envisages the construction of a $2 \mathrm{MW}$ electrolysis plant with hydrogen storage. Energy for electrolysis will be supplied from offshore wind turbines, hydrogen will be used as motor fuel for urban transport. 3) $\mathrm{SGH}_{2}$ - City of Lancaster, California. $\mathrm{SGH}_{2}$ is building the world's largest hydrogen waste gasification plant in Lancaster, California. It is reported that the technology is able to gasify for the production of hydrogen as well as plastic, tires and textiles. It is claimed that this produces "greener than green" hydrogen. With this technology, carbon emissions are three times lower than with electrolysis, and hydrogen is 5-7 times cheaper than that obtained by electrolysis and at the cost of production competes with "gray" hydrogen.

The commissioning of the plant is scheduled for 2023. By the way, it is believed that the cost of hydrogen derived from biomethane will be competitive with the cost of electrolytic hydrogen. 4) Fukushima Hydrogen Energy Research Field, Japan. The $180,000 \mathrm{~m}^{2}$ Hydrogen Research Field $\left(\mathrm{FH}_{2} \mathrm{R}\right)$ has been under construction in Fukushima County since 2018. A solar generator together with energy from the grid to power the world's largest hydrogen plant 10MW. The plant produces $1200 \mathrm{~nm}^{3}$ of hydrogen per hour and has equipment for storage and supply of hydrogen. 5) $\mathrm{H}_{2}$-Hub Gladstone facility - Queensland, Australia. The project differs in that the $175 \mathrm{~kW}$ electrolyzer is powered by the local RES network, hydrogen in a mixture with natural gas containing $10 \%$ hydrogen is supplied to industrial consumers through the existing gas network. This is the highest concentration of hydrogen supplied to the mixture through the existing network. The European Commission has announced that by 2024 the EU plans to create electrolysis plants with a capacity of at least $6 \mathrm{GW}$, which will produce up to one million tons of hydrogen. In the period 20252030, hydrogen should become the main component of the integrated European energy system, while the capacity of hydrogen hydrolysis stations should increase to $40 \mathrm{GW}$ with the ability to produce up to 10 million tons of pure hydrogen. In the next 2030-2050, hydrogen should become the EU's main energy resource and replace carbon, even in those sectors of the economy that are difficult to decarbonize.

\section{Transportation and storage}

The accumulation of energy produced by nuclear power plants and renewable sources in the form of hydrogen is associated with the problem of its storage and transportation. It is noted that hydrogen can be stored in containers at a pressure of 350-700atm. (35-70MPa), which is equivalent to the amount of energy stored in natural gas at a pressure of 20MPa. Vehicles use composite cylinders made of carbon fiber reinforced with aluminum or polymer fibers. The cost of such cylinders is almost equal to the cost of the vehicle. Regarding the transportation of hydrogen to the consumer in a compressed state in the conditions of its centralized production, one tubular truck weighing 40 tons can carry only $320 \mathrm{~kg}$ of hydrogen, compressed to $20 \mathrm{MPa}$, which is less than $1 \%$ of its own weight. In essence, the transportation of hydrogen in a compressed state is the transportation of containers. Liquid storage and transportation is very costly from both an energy and economic point of view. The liquefaction temperature of hydrogen is $20 \mathrm{~K}\left(-253^{\circ} \mathrm{C}\right)$. Its liquefaction consumes up to $40 \%$ of the energy contained in it. Liquid hydrogen has a high energy content - 120MJ/ $\mathrm{kg}(33.3 \mathrm{kWh} / \mathrm{kg})$ compared to gasoline - $44.4 \mathrm{MJ} / \mathrm{kg}(12.4 \mathrm{kWh} / \mathrm{kg})$. Tanks for transporting liquid hydrogen have a double body and vacuum insulation and have a high cost. Hydrogen losses due to evaporation during storage in the liquid state are estimated at 0.13 to $3 \%$ per day, depending on the volume of the tank. It is reported that with a capacity of several thousand cubic meters of hydrogen evaporation is $0.03 \%$ and in such containers hydrogen can be stored for up to 5 years. Power engineering magazine of March 30, 2020, citing Bloomberg, in an article entitled "Hydrogen-fired power promises carbon-free future but requires nearly $\$ 800$ B investment" emphasizes the need for high costs for hydrogen fuel in energy and estimates the cost of creating infrastructure for storage and transportation of hydrogen by 2050 in $\$ 637$ billion. Some authors believe that the transportation of energy in the form of hydrogen is economically more profitable than its transportation in the form of electricity, and that energy losses through the transportation of hydrogen are less than in the transportation of electricity. ${ }^{5}$ 


\section{Hydrogen in energy, transport, industry and households}

The main directions of hydrogen use are energy accumulation, use as motor fuel for stationary and transport engines, metallurgical processes, boiler plants, household needs, energy transport. The use of mixtures of hydrogen with natural gas can be promising. Projects of using hydrogen as a motor fuel with the production of fuel on board a vehicle using fuel cells are becoming more widespread. At this stage, such projects are demonstrative in nature, although the scale of the experiments is quite large. Hundreds of "hydrogen" pilot projects are being implemented in Germany, the United Kingdom, the United States, South Korea, Switzerland and other countries. The world's first trains on hydrogen fuel cells began running in Germany. In Japan, in 2013, the production of hybrid cars with fuel cells Toyota Mirai began. Hydrogen cylinders are located under the bottom of the car; fuel cells are cooled by air. Range up to $650 \mathrm{~km}$. In March 2020, the test of the French "hydrogen train" Alstom Coradia Lint was completed in the Netherlands. According to Power Engineering International on October 24, 2019, 13 hydrogen cars from five European countries have been run to Hamburg, Germany, to demonstrate "hydrogen mobility" and the benefits of driving hydrogen cars. The event was funded by the pan-European Hydrogen Mobility Europe $\left(\mathrm{H}_{2} \mathrm{ME}\right)$ project. More than half of the world's hydrogen fuel cell vehicles are currently being tested and used in the United States. The country has 550MW of fuel cell power plants and more than 8,000 hydrogen filling stations in 40 states. It should be noted that the transportation of such flammable and explosive gas on general purpose roads is dangerous in itself. Ulster University in Northern Ireland has studied various aspects of the safe use of hydrogen in vehicles. It was noted that the mechanical energy at the rupture of a cylinder with a capacity of 171 liters of hydrogen compressed to $350 \mathrm{bar}$ on a Honda Clarity car is equivalent to an explosion of $3 \mathrm{~kg}$ of TNT. When an 88-liter cylinder with a hydrogen pressure of 318 bar burst, a fireball with a diameter of 28 $\mathrm{m}$ was formed as a result of the fire and the car was thrown back by $22 \mathrm{~m}$. missing. With the same probability of fire, the risks for cars on hydrogen are higher than for cars running on fossil fuels. ${ }^{6}$

German companies Dillinger and Saarstahl are experimenting with hydrogen in blast furnaces. Hydrogen is extracted from coke oven gas. It is noted that further use of hydrogen will be possible if it will be sufficient hydrogen in the region on a competitive basis, as at this time the cost of hydrogen is ten times higher than the cost of natural gas. The works are sponsored by the German government. Swedish companies Ovako and Linde tested heating steel before rolling using hydrogen. It is noted that this did not affect the quality of the metal. At the same time, the World Steel Association has expressed doubts about the global transition to "green" steel by 2050 . The problem is the high cost of hydrogen. Roland Berger, a consulting firm, estimates the cost of switching to hydrogen in European metallurgy at 100 billion euros. Earlier, the European Commission announced a revision of the procedures for providing financial assistance from the budget for these purposes. An attractive use of hydrogen is the transport of energy through gas pipelines especially in mixtures with natural gas. Gas transmission system operators in a number of European countries presented a plan to build needed infrastructure by 2030 to provide Europe with clean fuel. The cost of creating this infrastructure is estimated at 27-64 billion euros. Approximately $75 \%$ of existing highways will be repurposed for hydrogen needs. The study of the possibilities of transporting mixtures of natural gas and hydrogen by main and distribution gas pipelines is also relevant for Ukraine. This seems expedient from the point of view of loading of the gas transmission system with such mixtures and their further transportation to the EU countries.
The study of the problem of transportation of hydrogen and its mixtures with natural gas through gas distribution networks is carried out in Ukraine on the initiative of RGK - a Regional Gas Company. The efficiency and environmental friendliness of the use of mixtures in household gas appliances - gas stoves and heating boilers are also studied. ${ }^{7}$ Preliminary test results of the research sites have shown that the existing networks are not suitable for transporting $100 \%$ hydrogen. At an average pressure of $0.4 \mathrm{MPa}, 46 \%$ of the pressure was lost in the first 14 days. Typical leaks were threaded and coupling joints using modern sealing materials, pressure sensor and regulator connections, and welds, including factory-made ones. Areas of low pressure, according to preliminary data, meet the requirements of tightness, because the pressure drop in them does not exceed $0.1 \% / \mathrm{h}$. At the time of testing of gas pipelines for tightness during transportation of mixtures of hydrogen with natural gas at hydrogen concentrations in the range of $10 \%-50 \%$.

\section{Hydrogen and climate}

The driver of hydrogen energy and the transition to a hydrogen economy in the future is the prevention of climate change due to global warming. Most scientists link global warming to carbon dioxide emissions from fossil fuel combustion products. The other part is of the opinion that the reason for the changes is not the shielding of the Earth's radiation by carbon dioxide, but is explained by phenomena of planetary scale. The main are the periodic deviation of the Earth's axis from the conditional central position, the periodic change in the activity of the Sun and the unpredictable frequent change in the direction of air circulation. Scientists' study of a significant amount of data on the role of various atmospheric gases in the planetary greenhouse effect has led to the following figures: water vapor $-80 \%$, small gaseous components of the atmosphere - methane, ozone, CFCs and others $-10 \%$, carbon dioxide - $10 \%$. Of this amount of dioxide, the share of anthropogenic in the total greenhouse effect is only $1 \%$. It must be noted that the concentration of water vapor in the atmosphere is measured in $\mathrm{g} / \mathrm{m}^{3}$, three orders of magnitude higher than carbon dioxide, the concentration of which is measured in $\mathrm{mg} / \mathrm{m}^{3}$. It is known that the absorption capacity of a layer of three or more atomic gases is proportional to the multiplication of the layer thickness and the partial pressure of the gas. The thickness of the layer for carbon dioxide and water vapor is the same - it is the height of the atmosphere. But the partial pressure of water vapor is three orders of magnitude greater than that of carbon dioxide. Taking into account the concentration distribution over the height, the mentioned difference in shielding seems reasonable. One can imagine that the American government agreed with the similar views of American scientists, as a result of which the United States withdrew from the Paris Climate Agreement. Former National Academy of Sciences President Professor Frederick Zeitz writes: "Experimental evidence on climate change shows no harmful effects of anthropogenic use of hydrocarbons. In contrast, there is strong evidence that increased carbon dioxide in the atmosphere is beneficial." Zeitz sent a petition by scientists to the U.S. government urging it to abandon the International Agreement on Global Warming. More than 15,000 American scientists and engineers signed the petition. ${ }^{8}$

Ukrainian geologists of the National Academy of Sciences of Ukraine and Naftogaz of Ukraine write about the predominant influence of polyatomic gases on the Earth's shielding. ${ }^{9}$ They point to the deep hydrocarbon degassing of the Earth, in which huge volumes of hydrocarbons pass through the Earth's crust on their way to the hydrosphere and atmosphere, and argue that "the talks about significant anthropogenic impact on greenhouse gas formation and 
global warming are unfounded." It is argued that "global warming due to human economic activity is only a scientific hypothesis that contradicts known facts from geology and climatology and is an instrument of a noisy group of scientists and politicians."

\section{Who benefits from the hydrogen boom}

Politicians who, against the backdrop of the struggle for decarbonization, want to look to the voters as saviors of humanity. Scientists and companies who want to receive grants from governments for research and demonstration projects on hydrogen. The European Union. To this end, the EU, as part of the Green Deal, is planning a Carbon Import Corrective Mechanism (CICM) - a new generation trade barrier. The European Commission is preparing a law to restrict imports into EU countries of goods produced using "dirty" energy, i.e. energy produced from carbon-containing fuels - coal, oil, natural gas. The legislative procedure will begin as early as June 2021. A likely format for a carbon barrier could be: internal tax in relation to carbonintensive goods; excise tax on turnover on the EU market, determined depending on the level of carbon emissions during the production of goods; quotas on greenhouse gas emissions, which importers would have to buy to bring their goods to the EU market. The law could benefit Russia. One of the scenarios in Germany's Energy Strategy calls for a complete phase-out of nuclear and coal-fired generation and a complete transition to renewable energy sources. To ensure the sustainability of the system, it is considered necessary to introduce shunting capacities on natural gas with a total capacity of more than $60 \mathrm{GW}$. This means increasing exports of natural gas from Russia and using the pipeline Nord Stream -2 under the Baltic Sea to their full capacity. A number of WTO members with large export potential are concerned about this EU decision. The major players in the European market, the U.S. and China, also took a negative stance, but expressed a willingness to negotiate. Each country has the right to use those energy resources that it possesses to a greater extent. And no one can impose on it, under the dubious pretext of decarbonization, those resources that lead to the deterioration of its economic situation and the lowering of people's living standards. In conclusion, the choice of direction for hydrogen energy and the hydrogen economy requires careful analysis and a great deal of research.

\section{Conclusion}

One of the main trends in world energy is the problem of hydrogen energy. A number of countries have adopted programs for the transition to hydrogen energy and hydrogen economy. The production of electrolytic hydrogen consumes more energy than can be obtained by using it. Economically viable technologies for the use of hydrogen do not yet exists. When replacing natural gas with hydrogen, its three times lower calorific value should be taken into account. Properties of hydrogen such as wide explosive limits, high torch propagation speed, corrosion activity against many metals require special measures during its transportation, storage and use. One of the promising hydrogen technologies for Ukraine may be the production of hydrogen through the use of nuclear energy and renewable energy and its export as part of mixtures with natural gas to European countries. Long-term tests of the suitability of gas pipeline materials for transporting mixtures are required for the reliable implementation of such technology. Significant funds are spent on hydrogen production, transportation, storage and use projects in the world. Each country has the right to use those energy resources that it possesses to a greater extent. Only a careful analysis and cycles of experimental research will allow to draw a general conclusion about the feasibility and cost-effectiveness of the chosen path.

\section{Acknowledgments}

None.

\section{Conflicts of interest}

The author declares that there is no conflict of interest.

\section{References}

1. Karp IM. Hydrogen in electric and transport power engineering. Technicheskaya electrodynamyka. 2020;1:64-70.

2. Aslanyan GS, Reutov BF. The problematic nature of the formation of hydrogen energy. Heat energy. 2006, 4:66-73.

3. Hydrogen: Five potential game-changers to watch. Power Engineering Intern. 2020:29:2-3.

4. Tommy I. HyDeploy: The UK's First Hydrogen Blending Deployment Project. Clean Energy. 2019;3(2):114-125.

5. Mytrova T, Melnikov Y, Chugunov D. The hydrogen economy is the way to low-carbon development. Center for Energy of the Moscow School of Management Skolkovo. 2019.

6. Shentsov V. Introduction to hydrogen safety e-laboratory and education. Presentation at Naftogas of Ukraine. 2019:62.

7. One step closer to hydrogen in gas networks. Economic Truth. 2020.

8. Gorodnitsky A. The end of the myth of global warming. Moscow. Noviye Izvestiya. 2017.

9. Gozhik P, Lukin O, Vdovichenko A, et al. A new theory of renewability, inexhaustibility and environmental friendliness of deep oil and gas resources. 2019 